\title{
The "Information Literacy Self-efficacy Scale" and the Medical Curriculum at Ghent University
}

\author{
Ann De Meulemeester \\ Knowledge Center Ghent, Ghent University \\ Ghent, Belgium \\ ann2.demeulemeester@ugent.be
}

\begin{abstract}
A study was conducted of all medical students $(n=1253)$ in the five first years of the medical curriculum of Ghent University. The study focused on the effect of learning in a medical undergraduate curriculum, in relation to the results of information literacy self-efficacy (ILSE) beliefs and information literacy skills. All students were invited to participate in an ILSE questionnaire and a progress test of information literacy (PTIL). Mean scores of ILSE and PTIL were evaluated. Spearman correlation was used to evaluate the consistency between ILSE and PTIL. Our findings indicate that the PTIL did not further increase after the second year, while the ILSE beliefs did. This brings us to the conclusion that information literacy training should be boosted throughout the entire curriculum.
\end{abstract}

Keywords: Self-efficacy, information literacy, medical curriculum, higher education, progress test.

\section{Introduction}

Information literacy (IL) is defined as "a set of abilities requiring individuals to recognize when information is needed and have the ability to locate, evaluate, and use effectively the needed information" [1]. IL enables learners to master content and extend their investigations, become more self-directed and get more control over their own learning. It forms the basis of lifelong learning. The learning path is common for all disciplines, learning environments and at all levels of education [1]. Information skills are essential for a successful academic track. Kılıç-Çakmak [2] indicated that many higher education institutions were launching projects to enhance the IL skills of students.

Pinto [3] defined three dimensions of educational activity: knowledge, skills and attitude. According to Bandura [4] self-efficacy (SE), or an individual's belief in her/his own ability to succeed in a specific task, is an important influencing factor of performance. Persistence or resilience is crucial for information problem solving, selfregulated learning and lifelong learning [5]. Research [6] confirmed that training of students to strengthen their SE and their belief to have the ability to determine their performance, can facilitate valuing effort and hard work. As contended by different researchers [7-9] the context or specific domain wherein SE is evaluated is considered 
to be important, as an individual can be more or less confident according to the discipline, domain or other situational differences. Qualitative research indicates that students gain a better appreciation of certain resources when they are discovered or introduced at a contextually appropriate point in their learning path. Teaching valuable use of non-medical and medical resources should therefore be introduced at relevant points in the curricula [10].

Students can become information literate only if they proactively and independently choose to pursue the opportunities that are available to them during the process of their education [2]. Consequently, education should be focused on both the development of IL skills and the attainment of a high sense of SE. Moreover Kingsley [11] advised incorporating IL training early in the curriculum, to help students develop their IL skills and SE. IL skills training should be integrated not only during the first two years of the curriculum, but also taught throughout the entire medical education, in order to enhance retention of IL and lifelong learning knowledge and skills [12].

\section{Background}

The purpose of this study was to investigate the relationship between the learning outcomes of IL training and SE within the medical curriculum (6 years) of Ghent University. Students starting at the medical faculty of Ghent University already passed an entrance exam for medicine. This exam is a major selection factor in the general competences of our study population. It consists of two parts: "knowledge and insight in sciences" and "acquiring and processing information".

Training in IL skills is integrated in the curriculum and examined at the end of each semester, when the course was scheduled. The curriculum provides combined courses of lectures and practice in IL skills until the 3rd year. This combination is important to activate learning within a context. Eskola [12] researched IL in the medical curriculum by describing learning methods. For the medical curriculum, problem-based learning is essential within the educational program. Problem-based learning uses students' initiative as a driving force; they have to define the subject, formulate the questions, provide the answers and teach to or share with other students.

Storie and Campbell [10] stated in 2012 that the development of IL skills is recognized as an important aspect of medical education and the practice of evidencebased medicine. Moreover information retrieval and critical appraisal of information have become important as medical education standards require medical students and residents to possess competency in those skills. Likewise the objectives of the medical curriculum of Ghent University include goals related to IL: "Physicians should possess skills and attitudes to acquire and process adequate information. Physicians should have the knowledge, skills and attitudes concerning scientific research: this concerns primarily skills in dealing with critical findings concerning scientific research, in finding relevant scientific information, in obtaining the ability to deal with "guidelines" and in developing a critical reading culture and awareness of the possibilities and limitations of scientific research." [13]. 
This research on the effect of learning in a medical undergraduate curriculum on the results of the ILSE beliefs and the IL skills is supported by the Commission of Education of the curriculum of medicine and has been approved by the Ethical Commission of the Ghent University and the University Hospital of Ghent.

\section{Data Collecting Tools}

All students were presented two tools, the Information Literacy Self-Efficacy (ILSE) questionnaire and the Progress Test in Information Literacy (PTIL). Students were confident they could answer without inhibitions, because all test results were made anonymous through a Trusted Third Party. In this way, the different test results can be linked anonymously at a student level and can be used for longitudinal research. SPSS statistics 21 was used to manage the data.

\subsection{Information Literacy Self-efficacy Scale}

Two different questionnaires were used to assess the ILSE competences. First a standardized ILSE- scale developed by Kurbanoglu, Akkoyunlu and Umay [5], composed of 7 factors and 28-items. The factors of the scale are determined as "defining the need for information", "initiating the search strategy", "locating and accessing the resources", "assessing and comprehending the information", "interpreting, synthesizing, and using the information", "communicating the information" and "evaluating the product and process". These skills are mandatory in a general context of IL or education. Secondly we administered a SE-questionnaire with 10 additional IL skills (basic to advanced) specific for medical sciences, as the context is considered important to evaluate SE. The personal degree of confidence is evaluated on a scale of $0-100$. The SE questionnaires were both conducted in English and every question was made mandatory.

\subsection{Progress Test on Information Literacy}

Simultaneously, IL skills were evaluated by a PTIL. Students of medicine in Ghent are familiar with progress tests, as every year in November they have to participate to a progress test in medicine [14]. Every student from study year 1-6, has to answer the same questions. The PTIL was especially developed in the same way and consists of 30 questions measuring basic to advanced skills of IL within a medical context. Every academic year a new set of questions is set together, evaluated by the head of the curriculum and by the Ethical Commission. The questions are set up in multiplechoice form, are mandatory and prepared in Dutch, the language of education.

\section{Cohort}

In the academic year 2012-2013, all medical students $(n=1253)$ from study year $1-5$ at Ghent University were invited to complete the different questionnaires (response rate of $77.5 \%$ ). The $6^{\text {th }}$ year of the curriculum will be investigated in June 2013, after their 
final clinical examination. All tests from study year 1-5, were conducted in the first two weeks of the academic year. In this way we will have results from students starting in their first week at university, as well as students ending their studies. All students were gathered in different groups, on campus, to fill in the questionnaires.

\section{Results}

The results for the academic year 2012-2013, presented in this paper are a part of an extensive longitudinal (2011-2014) research evaluating IL within the medical curriculum.

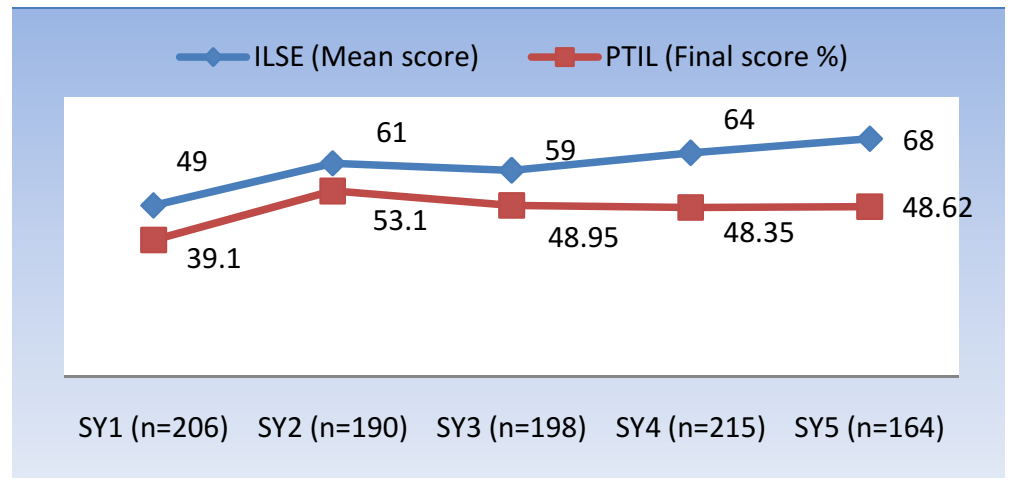

Fig. 1. Results by study year (SY) for the ILSE beliefs and the PTIL scores

We notice a low self-efficacy in year 1 which is normal as they have just started their academic career. The highest self-efficacy is in year 5 .

The PTIL scores in study year 2 are the highest, which is a result of an intensive course in the first year. Students were tested about their knowledge and are still aware of their skills. After the third year the skills are less tested and we see no further growth of their knowledge in IL.

Spearman correlation $\left(\mathrm{r}_{\mathrm{s}}\right)$ was used to evaluate the consistency between ILSE and PTIL in study year 1-5. We notice in study year 1-4 a positive and significant correlation and in study year 5 a negative and non-significant correlation $\left(r_{\mathrm{s}=} .104\right.$. $\mathrm{p}=.198)$.

If we compare the scores of both tests we note in the $5^{\text {th }}$ year a result we did not expect. Looking at the results of the SE mean score (68), we would suppose a much higher result of the PTIL (48.62\%). Students feel confident, but the IL test results do not indicate results similar to PTIL test results.

\section{$6 \quad$ Further Research}

Further detailed research is required. We will need to identify why the results of the first year students are higher than expected. Is it because the students guessed the answers correctly, or is it because the students already went through the entrance 
examination of "Acquiring and processing information". After every question of the PTIL, students were asked on a scale of 1 (I do not know the answer) to 5 (I am 100\% sure of my answer) if they were confident about the response they gave.

Research on the level of each individual question will be the next step, as we should analyze which problems, in gaining IL skills, come forward and in which study year. This will be monitored and will be taken in account for further determination of content for the future IL courses.

The cross-sectional design of the study, results in some inter-group variability (year 5). Longitudinal follow up is needed and planned.

\section{Conclusion and Discussion}

The results of the students' PTIL in higher stages of the curriculum are disappointing. The test is build up as a progress test, therefore students of the $5^{\text {th }}$ year should be familiar with all questions. Our finding that the PTIL scores did not further improve after the second year while ILSE beliefs did, makes us recommend that IL training should be boosted in the entire curriculum. As Eskola [12] stated, the skills should be taught throughout the entire medical education in order to enhance the retention of the knowledge and skills in IL. Students need to be instructed at the right time, when information is needed; consequently students will be motivated to learn. Integration of practice at all stages of the curriculum is necessary. Here lies the responsibility of the teachers. They need to be familiar with all aspects of IL and need to include the information resources in a structured way in their courses. IL is a responsibility of the entire faculty [15].

The results of the research are already being taken into consideration for an adaptation of the curriculum for the next academic year 2013-2014. Some parts instructed in the first year are moved to the third year and vice versa. The need to boost training is essential. Thus some important parts of the first year are going to be repeated in the third year. A manual for training in IL [16] within a medical context will be updated and republished in June 2013. The aim is to use the manual as a study framework throughout the whole curriculum. Students are getting guidelines in how to handle (locate, search, evaluate, publish...) scientific knowledge, and, moreover, medical information.

\section{References}

1. Association of College and Research Libraries: Information Literacy Standards for Higher Education. ACRL, Washington, DC (2000), http: / /www . ala org/ala /mgrps / divs/acrl/standards/informationliteracycompetency.cfm

2. Kılıç-Cakmak, E.: Learning Strategies and Motivational Factors Predicting Information Literacy Self-efficacy of e-Learners. Australasian Journal of Educational Technology 26(2), 192-208 (2010)

3. Pinto, M.: Design of the IL-HUMASS Survey on Information Literacy in Higher Education: A Self-assessment Approach. Journal of Information Science 36(1), 86-103 (2010) 
4. Bandura, A.: Self-efficacy: Toward a Unifying Theory of Behavior Change. Psychological Review 84, 191-215 (1977)

5. Kurbanoğlu, S.S., Akkoyunlu, B., Umay, A.: Developing the Information Literacy Selfefficacy Scale. Journal of Documentation 62(6), 730-743 (2006)

6. Komarraju, M., Nadler, D.: Self-efficacy and Academic Achievement: Why Do Implicit Beliefs, Goals, and Effort Regulation Matter? Learning and Individual Differences 25, 67-72 (2013)

7. Lin, T.-J., Tan, A.L., Tsai, C.-C.: A Cross-Cultural Comparison of Singaporean and Taiwanese Eighth Grader's Science Learning Self-Efficacy from a Multi-Dimensional Perspective. International Journal of Science Education 35(7), 1083-1109 (2013)

8. Bong, M., Skaalvik, E.M.: Academic Self-concept and Self-efficacy. How Different are They Really? Educational Research 29, 723-738 (2003)

9. Pajares, F.: Current Directions in Self-efficacy Research. In: Maehr, M.L., Pintrich, P.R. (eds.) Advances in Motivation and Achievement, vol. 10, pp. 1-49. JAI Press, CT (1997)

10. Storie, D., Campbell, S.: Determining the Information Literacy Needs of a Medical and Dental Faculty. Journal of the Canadian Health Libraries Association 33, 48-59 (2012)

11. Kingsley, K., Galbraith, G., Herring, M., Stowers, E., Stewart, T., Kingsley, K.V.: Why not Just Google It? An Assessment of Information Literacy Skills in a Biomedical Science Curriculum. BMC Medical Education 11, 17 (2011)

12. Eskola, E.L.: Information Literacy in Medical Education: Relationships with Conceptions of Learning Methods. Advances in Library Administration and Organization 25, 203-238 (2007)

13. Profiel van de Arts van de 21 ste eeuw, http: / / www . ugent. be/ge/nl/ onderwijs/opleidingen/gen/eindtermen

14. Interuniversitaire VoortgangsToets Geneeskunde, http: / /www . ivtg.nl

15. Verhaaren, H., De Meulemeester, A.: What is Important? Digital Literacy or Literacy in a Digital Environment? In: Remenyi, D. (ed.) Proceeding of the 8th European Conference on E-Learning, Bri, Italy, October 29-30, pp. 672-678. Academic Publishers, UK (2009)

16. Verhaaren, H.: Wegwijs in Kennis. Een Praktijkgerichte Inleiding tot de Informatiewetenschap. Acco, Leuven (2010) 